\title{
A Review of Users Adoption of Open Source Software in Africa
}

\author{
John Kamau ${ }^{1} \&$ Sylvester Namuye ${ }^{2}$ \\ ${ }^{1}$ Department of Information Technology, Mount Kenya University, Thika, Kenya \\ ${ }^{2}$ School of Science and Technology, United States International University, Nairobi, Kenya \\ Correspondence: John Kamau, Department of Information Technology, Mount Kenya University, Thika, P.O. \\ Box 342-01000, Kenya. Tel: 254-733-388-505. E-mail: jkamau@mku.ac.ke
}

Received: June 21, 2012 Accepted: July 11, 2012 Online Published: July 19, 2012

doi:10.5539/cis.v5n5p45 URL: http://dx.doi.org/10.5539/cis.v5n5p45

This research work was partially funded by Mount Kenya University

\begin{abstract}
In the current world, software is increasingly becoming important in the human activity. It is widely recognised that Open Source software (OSS) is freely available to anyone who needs it. However, loyalty of computer users to proprietary operating systems and general office applications seems to be still high especially in developing countries. OSS has a great potential of saving costs for developing economies in Africa and reducing the cost of doing business and automating operations. The software would be very useful especially in the current period of economic hardships being faced by many developing countries. African governments have also not taken the lead in adopting the OSS software and many do not have policies in place regarding it.

A review of literature on studies conducted in Africa on OSS in order to establish the level of user adoption, possible barriers to OSS adoption in developing countries in Africa is done in this paper. The findings are of great value to all stakeholders, namely the software developers, policy makers and computer experts in their endeavour to achieve high user adoption of OSS.
\end{abstract}

Keywords: open source software, adoption, economically developing countries

\section{Introduction}

Open source software is defined by Feller and Fitzgerald (2002), as where the source code of the program is made freely available for anyone to change and distribute provided they abide by the accompanying license. Linux is believed to be one of the most successful OSS whose project begun in 1991 by Linus Torvalds, a Finnish university student (Feller \% Fitzgerald, 2000).

Computer experts have widely adopted OSS across the globe with the global E-Commerce infrastructure relying heavily on OSS such as Apache, Sendmail, Linux among others (Madey et al., 2002). Open Source Software is believed to offer significant benefits compared to typical commercial products which often stress on advancement and updation of visible features in order to achieve marketing advantages (Kandar et al., 2011). Researchers have suggested that OSS offer benefits such as cost savings, security, flexibility of software and hence many international non-government organisations are increasingly supportive of OSS (Dudley-Sponaugle et al., 2007).

According to Negash et al. (2007), licencing proprietary software such as the Windows operating system and the Ms Office is prohibively high for Economically Developing Countries (EDC). Ghosh (2003) argues that a software cost can be equal to several months of a person's salary or, in many occassions, more than the annual income of an individual in an EDC. This would lead someone to believe that EDCs would adopt OSS in large numbers (Negash et al., 2007).

Majority of African states are EDCs and one would expect adoption of OSS to be a natural choice. On the contrary the adoption of OSS is limited despite the fact that the development organisations and international non governmental organisations (NGOs) have been emphasising the high potential of OSS in these countries (Reijswound \& Mulo, 2007). Among the EDCs outside Africa, there are several notable countries that have widely and successfully adopted OSS with their governemnts taking the lead. Laszlo (2007) suggests that the largest consumers of computer software are ussually the governments and they therefore have considerable influence on the software market. 
In this paper we will review literature on studies conducted in EDCs outside Africa that have successfully implemented OSS in order to establish the factors that contributed to the success of the OSS in these EDCs. Literature on studies conducted in Africa will also be reviewed to establish the level of user acceptance of OSS. The review will also establish the possible barriers of adoption and possible remedial measures that can be taken to mitiggate against the barriers identified in the review.

\section{OSS Adoption in Non-African EDCs}

According to Reijswound and Mulo (2007), many Non-African EDCs have successfully adopted OSS with Brazil taking the lead. In their view, Brazil was the first country in the world to pass a law regarding the use of OSS which paid off with some good levels of adoption notably in the states of Rio Grande do Sul and Pernambuco. According to Laszlo (2007), the decision to switch to OSS was a cost cutting measure because Brazillians spent $\$ 1.1$ billion every year on software licencing fees.

In China, which is classified by the IMF (2010) as an emerging and developing economy apart from being an advanced economy has widely adopted OSS. As part of a five year development plan, China identified software as a strategic sector for development (Dudley-Sponaugle et al., 2007). Laszlo (2007) also noted that China has been very aggressive in promoting Linux. As a result Linux adoption has been on the increase since the year 2000 with a notable steady growth of over $40 \%$ per year (Dudley-Sponaugle et al., 2007). They observed that the Chinese have benefited through OSS by reducing cases of piracy, Cost savings, flexibility among other benefits.

In India which is another emerging and developing economy (IMF, 2010), OSS is suported by the government and businesses (Dudley-Sponaugle et al., 2007). They noted that OSS groups in India are distributing free copies of desktop productivity software. The paper concludes that the Indians have enjoyed benefits such as, reduction of cases of piracy which is done due to high costs of software, cost reduction, ability to compete with wealthy countries among others. In a similar manner, Peru passed a law encouraging the procurement of free software by the government in 2005 whose main motivation was to gain free access to public information by the citizen Laszlo (2007).

\section{OSS Adoption in Africa}

African countries have recognised the importance of OSS in development. In February 2003, a foundation called Free Software and Open Source Foundation for Africa (FOSSFA) was launched in Geneva, Switzerland, whose vision is to promote the use of FOSS and the FOSS model in African development (Edward, 2008). The FOSSFA foundation and Linux signed an agreement in December 2009 to work together in the promotion of OSS in Africa (Nwakanma, 2009).

Among the African states, South Africa has been on the frontline in the official implementation of OSS as a strategy within the public sector (Laszlo, 2007). The South African government acknowledges that OSS is a viable alternative for proprietary software and this is evident by the approval of the OSS policy by the cabinet (Mtsweni and Biermann, 2008). They further cite that one of the salient points in the policy states that government departments should adopt and implement OSS unless proprietary software is demonstrated to be superior to OSS. In South Africa, expenditure for proprietary software licences amounted to R6 billion annualy which is channeled to foreign companies such as Microsoft (Gopalakrishnan, 2006). Several years after the government policy was passed not much had been achieved (Archibald, 2007).

A survey conducted by Mtsweni and Biermann (2008), between November 2007 to March 2008 in the governmnent departments indicated that despite the departments being aware of OSS, a majority of them still used proprietary software. The summary of the resuts of the study is shown in Figure 1.

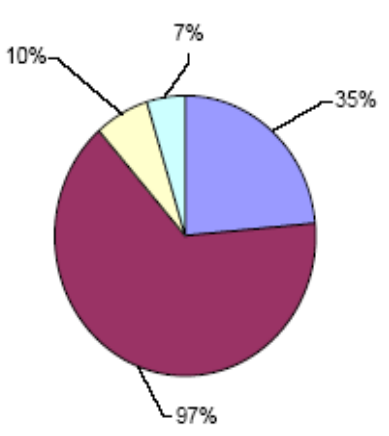

$\square$ Linux/Unix $\square$ Mcrosoft Windows $\square$ Sun Solaris $\square$ Mac OS

Figure 1. Operating systems on desktop computers

Source: Challenges affecting the OSS adoption rate in the SA government (Mtsweni \& Biermann, 2008). 
The results of the survey also indicated that the main challenge in the OSS adoption was non-compatibility with proprietary software (Mtsweni \& Biermann, 2008). Other challenges are shown in Figure 2 below.

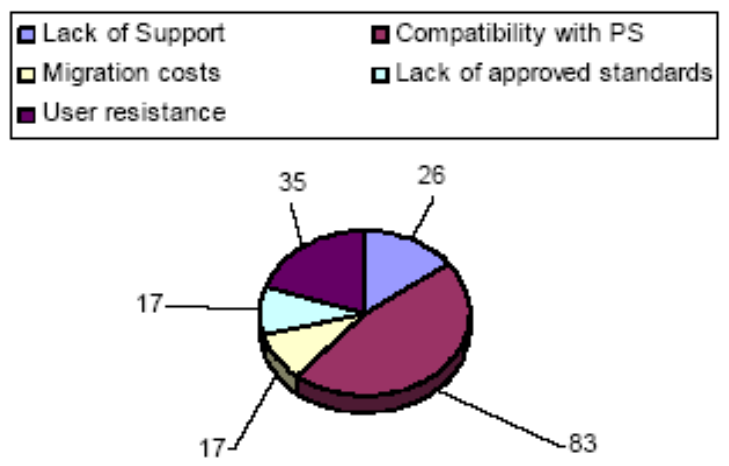

Figure 2. OSS implementation challenges in government

Source: Challenges affecting the OSS adoption rate in the SA government (Mtsweni \& Biermann, 2008).

Although OSS has been identified as a facilitator for small enterprises in emerging economies for the implementation of Information and Communication

Technology (ICT) infrastructure at reduced cost, its diffusion even in these enterprises has been notably slow (Ellis \& Belle, 2009).

In Botswana, which is one of the leading economies in Africa, OSS is not widely used (Mutula \& Kalaote, 2010). A study conducted by Mutula and Kalaote (2010), in the government ministriesindicated that the use of OSS is limited with only a few IT managers who had made individual efforts to spearhead its use. They further noted that Botswana did not have an OSS policy and that the government had made a long-term agreement with Microsoft for use of its products. A recent study indicates that majority of the companies in Botswana are not yet ready for OSS adoption and suggests that the Government Ministry of Transport and Communication has a major role to play in promoting OSS by implementing favourable policies for its adoption (Nyakudya, 2012).

Ghana is a country that has widely embraced technology, but in terms of OSS adoption the country is lagging behind with Microsoft windows operating system taking the lead at $84.7 \%$ and Linux at $11.9 \%$ (Amega-Selorm \& Awotwi, 2010). According to them some of the reasons given for the lead in the Microsoft operating system are; the Microsoft windows comes pre-installed in the computer, ease of use, availability of applications and availability of technical support. They cited absence of OSS adoption and procurement policy as a major adoption challenge of the software in the Government.

The adoption of OSS in Nigeria has been having the same challenges faced in other parts of the African continent with most computer users over relying on proprietary software (Adeyemo, 2005). He notes that the government has a role to play in promoting the use of OSS by assisting with Open source Research and Development, Education and Training.

A report on the status of OSS adoption in 2005 revealed that there was little use of OSS in most African countries both in the government and in the private sector (Bridges, 2005). The Bridges organisation also noted that an overwhelming majority of countries did not have policy on OSS. In most countries such as Uganda, Kenya, Benin, Burkina Faso, Cameroon, Ethiopia, Ghana among others there were some initiatives that were supporting the use of OSS, particularly in training institutions and universities (Bridges, 2005). The report also indicated that in Nigeria the government was investigating OSS as an alternative to proprietary systems in Government departments although sources indicated that the situation was being complicated by a generous Microsoft for software.

\section{Conclusion}

Although most decision makers are aware of the potential benefits of OSS such as cost saving, reduction of software piracy among others, the migration from proprietary to OSS is very limited. Surveys conducted in a number of African countries reveal a high use of proprietary desktop operating systems and general office applications. There is no doubt that companies such as Microsoft have been able to achieve customer lock-in in many countries in both the public and the private sector.

Several governments around the world have developed policies that encourage the adoption of OSS and have 
also taken the lead in adopting the same. In such countries OSS adoption has been on the increase. From the review it has been noted that governments are the world's largest consumers of computer software and have a considerable influence on the software market. If African governments were to have policies that encourage the use of OSS this would proliferate at a very high rate to the private sector.

Training institutions also have a major role to play because users need to be adequately trained on the use of desktop OSS. Without training users are likely to remain resistant to OSS regardless of the level of usability of the same. Organisations planning to implement OSS should ensure that there is good user support before the users get accustomed to OSS.

In countries with high levels of adaptability, there has been a deliberate move towards formulating framework on OSS and encouraging capacity development for its use. Further investigations need to be carried out in order to develop a model that will encourage African countries to adopt OSS.

Study limitations

Literature on the status of OSS adoption in Africa is limited and the existing one is not very recent. There is need to conduct surveys in African counties in order to obtain recent empirical data on OSS adoption levels and the barriers to its adoption.

\section{References}

Adeyemo, A. B. (2005). The Open Source Business Model and its Economic Implications for Nigeria and other Third World Economies. Journal of Information Technology Impact, 5(3), 121-128.

Amega-Selorm, C., \& Awotwi, J. (2010). Free and open source software (FOSS): it's significance or otherwise to the e-governance process in Ghana. ICEGOV '10: Proceedings of the 4th International Conference on Theory and Practice of Electronic Governance (pp. 91-95). ACM.

Archibald, J. (2007). SA Government's OSS plans revealed. Retrieved July 15, 2011, from Tectonic: http://www.tectonic.co.za/?p=1684

Bridges. (2005). Free/Open source software (FOSS) policy in Africa: A toolkit for policy-makers and practitioners. Retrieved from bridges.org

Dudley-Sponaugle, A., Hong, S., \& Wang, Y. (2007). The Social Economical Impact of OSS in Developing Countries. Handbook of Research on Open Source Software, 102-113.

Edward. (2008). History of FOSSFA. Retrieved July 8, 2011, from Free Software and Open Source Foundation for Africa: http://www.fossfa.net/node/5

Ellis, J., \& Belle, J. P. V. (2009). Open Source Software Adoption by South African MSEs: Barriers and Enablers. Conference of the Southern African Computer Lecturers' Association (pp. 41-49). New York: ICM.

Feller, J., \& Fitzgerald, B. (2000). A Famework Analysis of the Open Source Development Paradigm. ICIS 2000 proceedings of the twenty first international conference on information systems (pp. 1-12).

Feller, J., \& Fitzgerald, B. (2002). Understanding Open Source Software Development. Reading: Addison-Wesley.

Ghosh, R. A. (2003). License fees and GDP per capita: The case for open source in developing countries. First Monday, $8(12)$.

Gopalakrishnan, J. (2006). Lessons in Open Source Wisdom from South Africa. Linux for You, pp. 54-59.

IMF. (2010). IMF Emerging and Developing Economies List. World Economic Outlook Database APril 2010. Retrieved July 6, 2011, from International Monetary Fund: http://www.imf.org/external/pubs/ft/weo/2010/01/weodata/groups.htm\#oem

Kandar, S., Mondal, S., \& Ray, P. (2011). A review of Open Source Software and Open Source Movement in Developing Countries. International Journal of Computer Science \& Informatics, 1(1), 89-93.

Laszlo, G. (2007). Issues and Aspects of Open Source Software Usage and Adoption in the Public Sector. Handbook of Research on Open Source Software Technological, Economic, and Social Perspectives, 455-458.

Madey, G., Freeh, V., \& Renee, T. (2002). The Open Source Software Development Phenomenon: An analysis Based on Socila Network Theory. Eighth Americas Conference on Information Systems (pp. 1806-1812). 
Mtsweni, J., \& Biermann, E. (2008). Callenges affecting the OSS adoption rate in the SA government. Academic track of the 2008 Free and Open Source Software for Geospatial (FOSS4G) Conference (pp. 400-409). Cape town, Soth Africa: OSGeo.

Mutula, S., \& Kalaote, T. (2010). Open source software deployment in the public sector: a review of Botswana and South Africa. Library Hi Tech, 63-80. http://dx.doi.org/10.1108/07378831011026698

Negash, S., Carter, M., Chen, C., \& Wilcox, M. (2007). Open Source Software for Economically Developing Countries: A Free IT Solution for Sucess. Association for Information Systems Conference. (pp. 183-187).

Nwakanma, N. (2009). Linux fund and FOSSFA to join forces to promote open source software in Africa. Retrieved July 8, 2011, from Free Software and Open Source Foundation for Africa: http://www.fossfa.net/node/14?q=node/91

Nyakudya, M. N. (2012). Open Source Enterprise Applications in Botswana: A Readiness Assessment. International Journal of Engineering and Management Sciences, 32-42.

Reijswound, V. V., \& Mulo, E. (2007). Evaluating the Potential of Free and Open Source Software in the Developing World. Handbook of Research on Open Source Software Technological, Economic, and Social Perspectives, 79-92. 